\title{
Pandangan Masyarakat Terhadap Perkawinan Tongghâl Bhâllih Di Desa Bandaran Kecamatan Tlanakan Kabupaten Pamekasan
}

\author{
Akhmad Farid Mawardi Sufyan \\ R. AJ. Djamila Firdausy \\ (Institut Agama Islam Negeri (IAIN) Madura, email: \\ faridmawardi@iainmadura.ac.id)
}

\begin{abstract}
Abstrak:
Sebagian masyarakat Pamekasan melakukan perkawinan antara anak dari saudara laki-laki sekandung yang disebut dengan "Tongghâl Bhâllih". Penelitian awal di desa Bandaran kecamatan Tlanakan kabupaten Pamekasan terdapat praktik pelarangan perkawinan Tongghâl Bhâllih, namun perkawinan ini masih dilaksanakan oleh sebagian masyarakat. Adapun masalahmasalah yang dikaji dalam penelitian ini dirumuskan sebagai berikut : Pertama, Bagaimana Praktik Perkawinan Tongghâl Bhâllih di desa Bandaran kecamatan Tlanakan kabupaten Pamekasan. Kedua, Bagaimana Pandangan Masyarakat tentang Perkawinan Tongghâl Bhâllih di desa Bandaran kecamatan Tlanakan kabupaten Pamekasan. Penelitian ini menggunakan metode penelitian kualitatif dengan jenis penelitian fenomenologi. Hasil penelitian ini adalah Pertama, Praktik Perkawinan Tongghâl Bhâllih di desa Bandaran kecamatan Tlanakan kabupaten Pamekasan prosesinya harus dilaksanakan setelah jam 11:00 siang di rumah mempelai wanita sekaligus paman dari mempelai laki-laki. Kedua, Pandangan Masyarakat tentang Perkawinan Tongghâl Bhâllih di desa Bandaran kecamatan Tlanakan kabupaten Pamekasan ada yang menganggap tidak boleh, namun ada yang menilai boleh dilakukan selama sesuai ajaran Islam dan tanpa keraguan. (Some Pamekasan people carry out marriages between children of sibling brothers who are called "Tongghâl Bhâllih". Initial research in Bandaran village, Tlanakan sub-district, Pamekasan district, there is a practice of prohibiting Tongghâl Bhâllih
\end{abstract}


marriage, but this marriage is still carried out by some people. The problems studied in this research are formulated as follows: First, how to practice Tongghâl Bhâllih marriage in Bandaran village, Tlanakan sub-district, Pamekasan district. Second, how the community views Tongghâl Bhâllih marriage in Bandaran village, Tlanakan sub-district, Pamekasan district. This research uses qualitative research methods with the type of phenomenological research. The results of this study are First, the Tongghâl Bhâllih Marriage Practice in Bandaran Village, Tlanakan District, Pamekasan Regency, the process must be carried out after 11:00 in the afternoon at the house of the bride as well as the uncle of the groom. Second, The Community's View of Tongghâl Bhâllih Marriage in Bandaran Village, Tlanakan District, Pamekasan Regency, some think it is not allowed, but there are those who think it is permissible as long as it is according to Islamic teachings and without doubt.)

\section{Kata Kunci:}

Perkawinan Tongghâl Bhâllih, Bandaran, Pamekasan.

\section{Pendahuluan}

Perkawinan ialah akad yang menghalalkan pergaulan dan membatasi hak dan kewajiban antara seorang laki-laki dengan seorang perempuan yang bukan mahram. Allah SWT berfirman dalam surat an-Nisa' ayat 32:

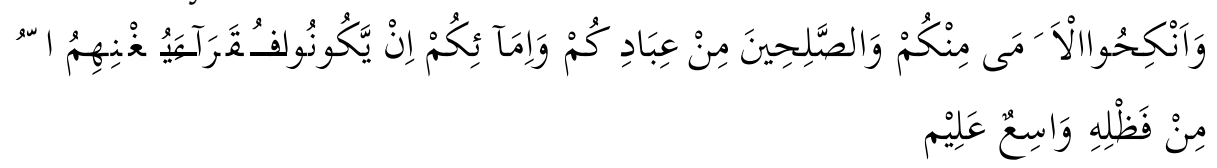

"Dan kawinkanlah orang-orang yang sendirian di antara kamu dan orang-orang yang layak (berkawin) dari hamba-hamba sahayamu yang lelaki dan hamba-hamba sahayamu yang perempuan. Jika mereka miskin Allah akan memampukan mereka dengan karuniaNya. Dan Allah Maha Luas (pemberiannya) lagi Maha Mengetahui".

Para fuqaha dan madzhab empat sepakat bahwa makna kawin adalah suatu akad atau suatu perjanjian yang mengandung arti tentang sahnya hubungan kelamin. Perkawinan adalah suatu perjanjian untuk melegalkan hubungan kelamin dan untuk melanjutkan keturunan. Dalam kitab fiqh, pembahasan pernikahan dimassukkan dalam suatu 
bab yang disebut munakahat, yaitu suatu bagian dari ilmu fiqh yang khusus membahas perkawinan untuk membedakannya dari bab-bab lain dengan masalah yang berbeda.

Di kalangan masyarakat Madura umumnya, dalam hal perkawinan biasanya akan mengutamakan dari kelompok sosialnya sendiri. Perkawinan yang menampakan kedudukan istri dalam kerabat lebih tinggi dari calon suaminya dianggap tabu. Ada juga perkawinan lainnya yang dianggap tabu, diantaranya: perkawinan saudara sekandung; perkawinan antara bapak ibu dengan anak-anaknya sendiri; dan perkawinan "sepopo pancer", yaitu perkawinan antara saudara sepupu dari dua bapak sekandung atau dua ibu sekandung. Adapun perkawinan yang umumnya terjadi adalah perkawinan yang bersifat monogami.

Werdisastra menyatakan bahwa: Untuk menjaga keakraban antar sesama kerabat agar tetap kuat, biaasanya dilakukan aktivitasaktivitas sosial, seperti saling mengunjungi, baik dalam keadaan suka (pertunangan, perkanikahan) maupun dalam keadaan duka (kerabat sakit, kematian, terkena musibah). Bahkan, untuk menjaga keutuhan dan menjalin kembali ikatan kekerabatan yang dianggap telah mulai longgar atau hampir putus karena proses perjalanan waktu, orang Madura mempunyai kebiasaan melakukan perkawinan antara anggota keluarga (kin group endogamy). Kebiasaan yang sampai saat ini masih tetap dipertahankan tampaknya telah berlangsung sejak jaman kerajaan, yaitu sekitar abad ke-13. Meskipun demikian, dalam kebudayaan Madura, ada juga perkawinan antara anggota keluarga yang harus dihindari, yaitu antara anak dari saudara laki-laki sekandung (sapopo) atau antara anak dari dua perempuan sekandung (sapopo) yang disebut arompak bhâllih atau tempor bhâllih. Menurut kepercayaan masyarakat Madura, jika perkawinan tersebut dilangsungkan maka akan membawa malapetaka bagi yang bersangkutan.

Namun di Madura, khususnya di kabupaten Pamekasan sebagian ada yang melakukan perkawinan antara anak dari saudara laki-laki sekandung yang disebut dengan istilahnya "Tongghâl Bhâllih" yang sampai sekarang budaya ini masih tetap berlangsunng. Perkawinan ini dilaksanakan karena masyarakat meyakini bahwa perkawinan tersebut tidak dilarang di dalam hukum Islam atau syariat. 
Peneliti melakukan penelitian awal di desa Bandaran kecamatan Tlanakan kabupaten Pamekasan, di desa ini terdapat praktik pelarangan perkawinan Tongghâl Bhâllih, namun perkawinan ini masih terlaksanakan oleh sebagian masyarakat di desa ini. Mengapa mereka tetap melaksanakannya, sedangkan adat melarang? Karena mereka tidak percaya adanya mitos bahwasanya perkawinan Tongghâl Bhâllih akan menimbulkan hubungan yang tidak harmonis seperti misalnya akan mempunyai keturunan yang cacat, salah satu dari suami atau istri meninggal dunia, meskipun bukan salah satu dari keduanya bisa terjadi terhadap kerabatnya. Bahkan juga akan mengalami kemandulan (tidak mempunyai keturunan). Dan juga menurut mereka karena orang tua laki-laki dari pihak suami (paman) bisa menjadi wali nikah pihak perempuan apabila sudah tidak memiliki nasab terdekat dari pihak perempuan. Selain tidak mempercayai mitos, mereka beralasan agar nasabnya tetap dalam satu keluarga besar tersebut. Artinya, mereka tidak ingin keluar dari pertalian nasabnya.

Dari uraian di atas peneliti berasumsi bahwa perkawinan Tongghâl Bhâllih ada kemungkinan berdampak positif maupun negatif. Sehingga peneliti di sini tertarik untuk meneliti tentang perkawinan Tongghâl Bhâllih tersebut dengan judul "Pandangan Masyarakat Tentang Perkawinan Tongghâl Bhâllih di desa Bandaran kecamatan Tlanakan kabupaten Pamekasan".

Berdasarkan latar belakang masalah tersebut di atas, maka disusunlah rumusan masalah sebagai berikut : pertama, bagaimana praktik perkawinan Tongghâl Bhâllih di desa Bandaran kecamatan Tlanakan kabupaten Pamekasan? Kedua, bagaimana pandangan masyarakat tentang Perkawinan Tongghâl Bhâllih di desa Bandaran kecamatan Tlanakan kabupaten Pamekasan?

\section{Metode Penelitian}

Penelitian ini menggunakan pendekatan kualitatif (qualitative approach). Peneliti melihat fenomena yang berkembang sebagai satu kesatuan yang utuh, yang tidak terikat dengan satu variable atau hipotesis tertentu. Pendekatan ini akan memudahkan peneliti dalam menemukan persoalan-persoalan ganda, mendekatkan diri peneliti dengan subyek yang diteliti, serta lebih peka dan lebih dapat 
menyesuaikan diri terhadap pengaruh fenomena yang ada di lapangan.

\section{Gambaran Umum Adat Istiadat antar Perkawinan antar Saudara}

Perkawinan adalah salah satu ritus peralihan yang sangat penting dalam kehidupan manusia. Dalam artian orang Madura, perkawinan sebagai kegiatan pemaduan dua keluarga menjadi suatu satuan yang jauh lebih besar lagi. Oleh karena itu, suatu perkawinan perlu melalui tahap-tahap untuk memungkinkan dilakukannya penjajakan dan pengukuran, tidak saja keserasian kedua calon pengantin, tetapi juga keselarasan dan kesetaraan kedua belah pihak keluarga yang akan dipersatukan.

Upacara yang dilakukan sebelum perkawinan

Pinangan merupakan bagian dalam upacara pernikahan. Upacara ini dilakukan ketika seorang pria hendak meminang gadis pujaannya. Tahap yang dilakukan sebagai berikut.

Pertama, keluarga pihak pria mengutus seseorang untuk nylabbhâr atau mencari kabar tentang status gadis yang akan dipinang. Setelah tiba ditempat tujuan, utusan menanyakan gadis yang akan dipinang dengan bahasa kiasan, misalnya: "Apakah bapak mempunyai rumput yang bagus dan apakah rumput itu sudah ada pemiliknya?" Jika rumput belum ada pemiliknya, maka pihak pria akan mengungkapkan maksud kedatangannya.

Kedua, beberapa hari kemudian, pihak pria bertamu lagi untuk menyampaikan kabar bahwa calon besan (disertai rombongan) akan bersilaturahmi. Jumlah rombongan yang akan hadir harus disebutkan, tetapi penyebutannya pun bukan angka sesungguhnya. Apabila yang akan hadir dua orang, maka jumlah yang sebenarnya dua puluh. Demikian pula jika sepuluh, maka jumlah sebenarnya adalah seratus orang.

Ketiga, rombongan dan calon besan datang dengan membawa beragam macam hantaran yang bermakna simbolik, bâjhik bermakna becik 'baik'), tēttēl (dibuat dari ketan, merupakan simbol perekat,bahwa kedua belah pihak akan menjadi rekat), sērē pēnang (simbol dari ungkapan menaksir lalu dipinang). Sērē pēnang kemudian dimakan, setelah dikunyah kemudian diludahkan. Ludahnya yang berwarna merah dimaknai sebagai anak. Dengan 
demikian pernikahan tersebut diharapkan memiliki anak-anak sebagai hasil persatuan cinta kasihnya.

Keempat, jika pria yang meminang ingin agar pernikahan segera dilaksanakan, maka dalam hantaran terdapat pisang susu, maksudnya kesusu atau ingin segera menikah.

Kelima, sebagai balasan atas pinangan, pihak wanita kemudian memberi oleh-oleh berupa lappet (makanan tradisional yang terbuat dari beras ketan, kelapa dan biji kacang panjang), maknanya adalah jawaban bahwa apa yang diberikan pihak pria sudah diikat di dalam hati keluarga pihak wanita (lamaran diterima).

Pengertian Saudara

Ikatan kekerabatan dalam masyarakat Madura terbentuk melalui keturunan-keturunan baik dari keluarga berdasarkan garis ayah maupun garis ibu (paternal dan maternal relatives). Tapi, pada umumnya ikatan kekerabatan antar sesama anggota keluarga lebih erat dari garis keturunan dari ayah sehingga cenderung "mendominasi". Pengertian Perkawinan dalam Islam

Perkawinan adalah jalan yang ditetapkan oleh Islam untuk mengatur kehidupan rumah tangga dan keturunan. Menurut bahasa, nikah berarti penyatuan. Berarti dapat dikatakan sebagai jalan perkenalan antara suatu kaum dengan kaum lainnya.

Rukun Perkawinan

Perkawinan dianngap sah bila terpenuhi syarat dan rukunnya. Rukun nikah merupakan bagian dari segala hal yang terdapat dalam perkawinan yang wajib dipenuhi. Jika tidak terpenuhi pada saat berlangsung, perkawinan tersebut dianggap batal. Dalam Kompilasi Hukum Islam pasal 14, rukun nikah terdiri atas lima macam, yaitu:

Calon Suami.

Calon Istri.

Wali Nikah.

Dua Orang Saksi.

Ijab dan Kabul.

Larangan Perkawinan

Dalam perkawinan ada beberapa hal yang harus diperhatikan. Kedua mempelai disyaratkan merupakan pasangan yang halal untuk menikah. Oleh karena itu, dalam al-Quran disebutkan tentang 
pasangan yang haram dinikahi. Adapun pasangan-pasangan yang haram atau mahram adalah sebagai berikut:

Pertama, tujuh orang dari pihak keturunan. Yakni ; Ibu dan ibunya (nenek), ibu dari bapak, dan seterusnya sampai ke atas, Anak dan cucu, dan seterusnya, Saudara perempuan seibu sebapak, sebapak, atau seibu saja, Saudara perempuan dari bapak, Saudara perepmpuan dari ibu, Anak perempuan dari saudara laki-laki dan seterusnya, dan anak perempuan dari saudara perempuan dan seterusnya,

Kedua, dua orang dari sebab menyusui, yaitu ; Ibu yang menyusui dan Saudara perempuan sepersusuan.

Ketiga, Lima orang dari sebab pernikahan, yakni ; Ibu istri (mertua), Anak tiri, apabila sudah campur dengan ibunya, Istri anak (menantu), dan Istri bapak (ibu tiri).

\section{Tradisi}

Istilah tradisi sering digunakan dan dijumpai dalam berbagai literatur, seperti tradisi madura, tradisi jawa, tradisi keraton, tradisi petani, dan tradisi pesantren. Dalam khazanah indonesia tradisi berarti segala sesuatu seperti adat, kebiasaan, ajaran, dan sebagainya, yang turun temurun dari nenek moyang, atau segala sesuatu yang ditransmisikan, diwariskan oleh masalalu ke masa sekarang.

\section{Kondisi Geografis Desa Bandaran.}

Desa Bandaran berada di sebelah Selatankota Pamekasan \pm 9 $\mathrm{km}$ dan berada di sebelah selatan dari kecamatan Tlanakan $\pm 17 \mathrm{~km}$. Terdiri dari daratan dengan luas wilayah $\pm 1.286,160$ Ha. Yang terdiri dari:

$$
\begin{array}{lll}
\text { Tanah sawah } & : \text { - irigasi sederhana } & : 50,0 \mathrm{Ha} . \\
& : \text { - tadah hujan / sawah rendengan } & : 142,0 \mathrm{Ha} . \\
\text { Tanah kering } & : \text { - pekarangan / bangunan } & : 224,2 \mathrm{Ha} . \\
& : \text { - tegal / kebun } & : 756,7 \mathrm{Ha} . \\
\text { Tanah hutan } & : \text { - hutan produktif / lindung } & : 75,0 \mathrm{Ha} . \\
\text { Tanah umum } & : \text { - kuburan / sekolah } & : 2,16 \mathrm{Ha} . \\
& : \text { - tanah bengkok } & : 20,04 \mathrm{Ha} .
\end{array}
$$

Dengan wilayah yang cukup luas tersebut. Jumlah penduduk Desa BandaranKecamatan Tlanakanterdiri dari \pm 14.792 orang, dengan perincian diantaranya 7.356 laki-laki dan 7.436 perempuan dengan 
jumlah kepala keluarga sebanyak 3.521. Yang keseluruhan terbagi dalam 11 dusun.

Kondisi Sosial Keagamaan

Dilihat dari kondisi sosial keagamaan masyarakat di Desa Bandarantergolong daerah yang cukup religius, bisa dilihat dari banyaknya Masyarakat Bandaran yang alumni pondok pesantren seperti alumni Pondok pesantren Banyuanyar, Bata-Bata, Ummul Quro, al-Mujtama', dan lain sebagainya.

Tidak hanya itu, di Desa Bandaranjuga banyak diadakan kegiatan keagamaan seperti koloman (pengajian) seperti: koloman malam selasa, malam mingguan, sebelasan, dan malam jum'at manis. Ada pula kegiatan muslimatan yang diadaklan tiap hari rabu dan kamis.

Kondisi Kemasyarakatan Bandaran merupakan masyarakat yang sangan bersosialisasi. Tidak heran antara penghuni rumah yang satu dengan rumah yang lainnya saling mengenal walaupun jarak rumah mereka berjauhan. Bukan hanya itu saja, gotong royong antara masyarakat yang satu dan yang lainnya pun juga tinggi, terlihat ketika ada acara atau ada tetangga yang tertimpa musibah, para tetangga datang untuk membantu.

\section{Temuan Penelitian}

Hasil dari peneliti melakukan wawancara dan observasi di lapangan. Ada beberapa temuan penelitian yang peneliti dapatkan. Sebagaimana yang dipaparkan berikut ini:

Peneliti menemukan bahwa masyarakat yang melaksanakan Perkawinan Tongghâl Bhâllih berawal dari saran tetua dan prosesi akad nikah yang dilaksanakan sama seperti pernikahan pada umumnya.

Peneliti menemukan bahwa perkawinan tongghâl bhâllih atas kehendak sendiri dan dorongan orang tua.

Peneliti menemukan bahwa perkawinan tongghâl bhâllih tidak ada yang perlu dikhawatirkan karena semua takdir hanya Allah Swt yang mengatur.

Peneliti menemukan bahwa dampak negatif dalam perkawinan tongghâl bhâllih antara mertua dan menantu tidak ada kesungkanan untuk menegur langsung. 
Peneliti menemukan bahwa perkawinan tongghâl bhâllih dilakukan supaya anak gadisnya mempunyai suami dari keluarga yang jelas bibitnya dan menjadi keluarga yang tentram.

Pandangan masyarakat tentang Perkawinan Tongghâl Bhâllih yang dilaksanakan oleh masyarakat di Desa Bandaran sebagaimana berikut:

Pertama, Masyarakat membolehkan perkawinan Tongghâl Bhâllih selama perkawinan tersebut sudah sesuai dengan ajaran agama Islam dan dengan penuh keyakinan.

Kedua, Masyarakat juga ada yang melarang dengan alasan bahwa Perkawinan Tongghâl Bhâllih bisa mengakibatkan anak keturunanya cacat dan kehidupan keduanya tidak harmonis.

\section{Penutup}

Dari beberapa hal yang telah peneliti paparkan dalam bab-bab sebelumnya, maka dapat diambil beberapa kesimpulan terkait Tradisi Praktik Perkawinan Tongghâl Bhâllih di desa Bandaran Kecamatan Tlanakan Kabupaten Pamekasan yakni sebagai berikut:

Pertama, Praktik Perkawinan Tongghâl Bhâllih di desa Bandaran Kecamatan Tlanakan Kabupaten Pamekasan prosesi akadnya harus dilaksanakan setelah jam 11:00 siang di rumah mempelai wanita sekaligus paman dari mempelai laki-laki.

Kedua, Pandangan Masyarakat tentang Perkawinan Tongghâl Bhâllih di desa Bandaran kecamatan Tlanakan kabupaten Pamekasan ada yang menganggap tidak boleh, namun ada yang menilai boleh dilakukan selama sesuai ajaran Islam dan tanpa keraguan.

\section{Daftar Pustaka}

al-Zuhaily, Wahbah., al-Figh al-Islam wa Adillatuhu, Juz 7, (Damaskus: Dar al-Fikr, 1989).

Engels, Frederick., Asal-Usul Keluarga, Kepemilikan Pribadi dan Negara, terj. Vidi (Jakarta: Kalyanamitra, 2004)

Hazairin, Hukum Kewarisan Bilateral Menurut al-Quran, (Jakarta: Tintamas, 1982).

----------, Hukum Kekeluargaan Nasional, (Jakarta: Tintamas, 1982) 
Hosseini, Ziba Mir., Perkawinan dalam Kontroversi Dua Madzhab: Kajian Hukum Keluarga dalam Islam, terj. Marriage and Trial: a Study of Islamic Family Law, (Jakarta: ICIP, 2005).

Kamil, Ahmad. dan Fauzan, Hukum Perlindungan dan pengangkatan Anak di Indonesia, (Jakarta: Rajawali Pers, 2008)

Karim, Khalil Abdul., Syariah: Sejarah, Perkelahian, Pemaknaan, Terj. Kamran As'ad, (Yogyakarta: LKIS, 2003).

Koentjaraningrat, Beberapa Pokok Antroplogi Sosial, (Jakarta: Dian Rakyat, 1976).

Mulia, Siti Musdah., Muslimah Reformis: Perempuan Pembaru Keagamaan, (Bandung: Mizan, 2005).

Muzarie, Mukhlisin., Kontroversi Perkawinan Wanita Hamil, (Yogyakarta: Pustaka Dinamika, 2002).

Nasution, Khoirudin., Hukum Perdata (Keluarga) Islam Indonesia dan Perbandingan Hukum Perkawinan di Dunia Muslim: Studi Sejarah, Metode Pembaruan dan Materi \& Status perempuan dalam Perundang-Undangan Perkawinan Muslim, (Yogyakarta: ACAdeMIA+TAZZAFA, 2009)

Qodri, Anwar A., Islamic Jurisprudence in The Modern World, (Lahore: Premier Book House, 1973) 